\title{
Children's Rights and the Non-Identity Problem
}

Can appealing to children's rights help to solve the non-identity problem in cases of procreation? A number of philosophers have answered affirmatively, arguing that even if children cannot be harmed by being born into disadvantaged conditions, they may nevertheless be wronged if those conditions fail to meet a minimal standard of decency to which all children are putatively entitled. This paper defends the tenability of this view by outlining and responding to five prominent objections that have been raised against it in the contemporary literature: (1) the identifiability objection; (2) the non-existence objection; (3) the waiving of rights objection, (4) the lack of legitimate complaint objection; and (5) the unfairness objection.

Keywords: children's rights; non-identity problem; rights-based solutions; procreative ethics; birthright claim

\section{Introduction}

In a brief passage toward the end of On Liberty, John Stuart Mill (1991, 120) considers the application of his liberty principle to the issue of procreation, claiming,

\footnotetext{
It is not in the matter of education only, that misplaced notions of liberty prevent moral obligations on the part of parents from being recognized, and legal obligations from being imposed, where there are the strongest grounds for the former always, and in many cases for the latter also. The fact itself, of causing the existence of a human being, is one of the most responsible actions in the range of human life. To undertake this responsibility — to bestow a life which may be either a curse or a blessing - unless the being on whom it is to be bestowed will have at least the ordinary chances of a desirable existence, is a crime against that being.
}

Mill's views on procreative responsibility have a strong intuitive pull. Even if individuals have a presumptive right to procreative liberty, it still seems wrong to create a child who will face serious restrictions on the quality of her life, and the putative wrongness of that 
action seems explainable in terms of that child's interests - it looks, in Mill's terms, like 'a crime against that being'. However, the precise nature of this crime has proven notoriously difficult to make sense of. Initially, it is tempting to claim that the crime consists in harming the child in the standard comparative sense of setting back her interests. On this interpretation, bringing a child into disadvantaged conditions is wrong because it makes that child worse off than she otherwise would have been had her parents brought her into decent conditions instead. However, as Derek Parfit (1984) and others have noted, this interpretation overlooks the fact that a child's identity is dependent on the particular act of procreation that brought her about. Had her parents delayed conception until a more favourable time, this would not have improved her condition, but would rather have resulted in a different child altogether, one composed of a unique set of reproductive gametes. The supposed crime to which Mill makes reference therefore appears to be a victimless one, as there is no identifiable individual who is made any worse off than they otherwise would have been.

A number of philosophers have argued that this problem can be circumvented in certain cases by appealing to a child's right to be born into minimally decent conditions (Archard, 2004; Elliot, 1989; Smolkin, 1999; Steinbock, 2009; Woodward, 1986). According to this view, even if children cannot be harmed by being born into disadvantaged conditions, they may nevertheless be wronged if those conditions fail to meet a minimal standard of decency to which all children are putatively entitled. This rights-based approach is in many ways attractive as a partial solution to the non-identity problem, though it has often been dismissed on the basis of well-known counterarguments. Critics have argued, for example, that rights cannot be intelligibly ascribed to children who do not yet exist; that disadvantaged children would retrospectively waive their rights to the extent they are happy to be alive; that children would lack a legitimate complaint about the 
violation of their rights insofar as their only alternative was non-existence; and that a rights-based approach leads to unacceptable normative implications, e.g. that the poor or destitute should not have children. I argue in this paper that each of these counterarguments is less persuasive than it initially appears, and that each may be convincingly rebutted within a rights-based framework. In this sense, my arguments can be understood as offering a novel defence of an existing but often-maligned view.

The paper proceeds in three parts. In Part 1, I outline the non-identity problem and the central challenge that it poses in the context of procreative ethics, namely, that a child cannot be harmed by a procreative act insofar as their existence depended on that act taking place. In Part 2, I explain how an appeal to rights gets around this problem by accounting for the moral wrong in non-identity cases without insisting that the child has been made comparatively worse off. I also address the concern that an appeal to rights in this context is ad hoc. Finally, in Part 3, I outline and respond to five prominent objections that have been raised against rights-based solutions in the contemporary literature: (1) the identifiability objection, (2) the non-existence objection, (3) the waiving of rights objection, (4) the lack of legitimate complaint objection; and (5) the unfairness objection.

\section{The Non-Identity Problem}

The non-identity problem arises in cases where an act that apparently harms a person is also a necessary condition for their existence. It is generated from the mundane fact that a person's numerical identity is tied to the timing of conception, such that if your parents had not conceived when they in fact did, the resultant child would not have been you, but a numerically distinct 'non-identical' child composed of a unique set of reproductive gametes. Parfit $(1984,351)$ expresses this fact as the Time-Dependence Claim, which holds that 'If any particular person had not been conceived when he was in fact 
conceived, it is in fact true that he would never have existed'. According to Parfit and others, the Time-Dependence Claim forces us to concede that so long as a person has a life worth living, he cannot be harmed by a set of actions or choices that lead to his conception, for his very existence depended on that conception taking place when it did.

The full force of the non-identity problem is felt in cases where our actions or choices cause a person to be born into disadvantaged conditions. While our gut reaction may be to claim that such actions or choices are wrong - and wrong in light of the adverse effects on the person who results - the non-identity problem complicates this inference. Because a person's numerical identity is tied to the timing of conception, they often owe their existence to the very act that appears to harm them-for had that act not been performed, they may never have been conceived, and in this sense are not made any worse off than they otherwise would have been. The logic of the non-identity problem is best illustrated through a series of hypothetical cases designed to show that an apparently harmful act is not in fact worse for anyone. As a paradigm non-identity case, consider Parfit's (1984, 358) 14-Year-Old Girl:

14-Year-Old Girl: This girl chooses to have a child. Because she is so young, she gives her a child a bad start in life. Though this will have bad effects throughout the child's life, his life will, predictably, be worth living. If this girl had waited for several years, she would have had a different child, to whom she would have given a better start in life. ${ }^{1}$

What is puzzling about 14-Year-Old Girl and other non-identity cases is that there seems to be a clear moral wrong that has taken place, yet no identifiable person who is made any worse off than they otherwise would have been. Due to Time-Dependence, the circumstances that the girl's child was born into were the best the he could have hoped for. Had the girl waited until she was older and more mature, the resultant child would not 
have been him, but rather a different child altogether, one composed of a unique set of reproductive gametes. Assuming that his disadvantaged life is preferable to no life at alleven marginally - he has not been made any worse off than he otherwise would have been. The challenge, then, is in articulating what, if anything, was wrong with his mother's decision.

The non-identity problem is often presented as a fact that poses an insurmountable challenge to claims of wrongdoing to future persons, though it actually relies on three contestable assumptions, the combination of which generates a paradox:

(1) the act in question is morally objectionable;

(2) for an act to be morally objectionable, it must wrong a particular person;

(3) for an act to wrong a particular person, it must make them comparatively worse off.

The puzzle of non-identity cases arises from the fact that, while each of these assumptions is intuitively appealing, they cannot all be held at once. Thus, responses to the non-identity problem have mostly centred along three lines, with each challenging or dispensing with a particular assumption.

First, some theorists have dispensed with (1), and simply conceded that the act in question is not in fact morally objectionable (Boonin, 2014; Heyd, 1992; Schwartz, 1978). This set of views retains assumptions (2) and (3), and holds that a morally objectionable act must make a particular person worse off than they otherwise would have been. On the basis of these assumptions, it deduces that because a particular person did not exist at the time of the act in question, and would not have existed had the act not been performed, they cannot be made worse off by the act, and so the act must therefore be morally 
permissible. In its strongest guise, this set of views yields the blunt conclusion that future persons who depend on our choices for their existence have 'no moral status of any kind, not even a weak one' (Heyd, 1992, 99).

Second, some theorists have dispensed with (2) and insisted that an act can be morally objectionable without wronging any particular person (Parfit, 1984; Brock, 1995; Feinberg, 1992). According to this set of views, the moral failing in non-identity cases does not consist in violating a duty to any particular person, but rather in violating a duty to promote certain impersonal values, such as utility or beneficence. On this view, the moral wrong in cases like 14-Year-Old Girl does not consist in causing harm to the particular child who results, but rather in failing to create a better off child in his place, or in 'wantonly introducing a certain evil into the world' (Feinberg, 1992, 27).

Finally, some theorists have dispensed with (3), and have argued that an act can wrong a particular person without making them worse off. There are several variations on this line of response. First, some theorists have denied that a person must be made worse off in order to be harmed - that is, they have rejected a comparative conception of harm in favour of a non-comparative conception (Harman, 2004; Shiffrin, 1999). On this understanding, harm does not consist in being made worse off than one otherwise would have been, but rather in being subjected to non-comparatively harmful states, such as 'pain, early death, bodily damage, or deformity' (Harman, 2004, 93) among others. Adopting a non-comparative conception of harm allows theorists to claim that the moral wrong in non-identity cases does consist in causing harm to the particular person who results, even if that person is not made worse off than they otherwise would have been.

Alternatively, other theorists have distinguished between harm and wrongdoing, and have argued that even if a person cannot be comparatively harmed in non-identity cases, they may nevertheless be wronged. One set of views locates the moral wrong 
purely in the actions or attitudes of the agents in non-identity cases, e.g. through their lack of concern or respect for the person born into disadvantaged conditions (Kavka, 1982; Kumar, 2003; Velleman, 2008; Wasserman, 2005). Another set of views locates the moral wrong in the not-worse-off consequences for the apparent victim in non-identity cases, e.g. in their being born into conditions that fall below a minimally decent welfare threshold to which all persons are putatively entitled (Archard, 2004; Elliott, 1989; Smolkin, 1999; Steinbock, 2009; Woodward, 1986).

My limited aim in this paper is to defend the tenability of one variation of this third line of response, namely, that the moral wrong in cases like 14-Year-Old Girl can be plausibly understood in terms of violating the child's right to be born into minimally decent conditions. Successfully defending this solution is sufficient to show that the first line of response is false, though it does not show, nor is it intended to show, that any other line of response is false. The rights-based view defended in this paper is consistent with a pluralistic approach toward non-identity cases that takes a range of impersonal and person-affecting considerations into account when evaluating their putative moral wrongness. However, since my aim in this paper is to substantiate the view that children may be wronged in a person-affecting sense when they are born into disadvantaged conditions, I will set aside discussion of alternative solutions and focus my attention on defending what I take to be a plausible rights-based solution.

\section{Rights-Based Solutions}

How, then, does such a solution work? As noted previously, all rights-based solutions begin with the more general premise that, contrary to assumption (3), a person can be wronged by an act without being made comparatively worse off by it. This is a crucial premise, as it allows for the possibility that a child may be wronged by being born into 
disadvantaged conditions even if they are not made any worse off than they otherwise would have been. Many theorists have taken this premise to be clearly false, claiming that if what we are doing will not be worse for a particular person, or will even be better for a particular person, then we are not in a morally relevant sense wronging that person (Parfit, 1984, 374; Brock, 1995, 271). However, as James Woodward (1986, 809-811) and others have noted, there are many instances in which this premise seems to be clearly true, including basic instances of rights violations (see also Kumar, 2003, 99-105; Smolkin, 1999, 199-202). Consider, for example, Woodward's $(1986,811)$ case of Smith:

\footnotetext{
Smith: Suppose that Smith, who is black, attempts to buy a ticket on a certain airline flight, and that airline refuses to sell it to him because it discriminates racially. Shortly after, that very flight crashes, killing all aboard.
}

Clearly the airline's refusal has left Smith, on balance, better off than he otherwise would have been, for had he boarded the aircraft, he would have died along with the other passengers. However, even though Smith has not been made comparatively worse off by the airline's refusal, he has nevertheless been wronged by being stigmatized and treated unequally on the basis of his race. His right to non-discrimination has been violated, and he retains a legitimate complaint against the airline even if its refusal left him better off than he otherwise would have been.

More familiar examples arrive at the same point. Factories operating in developing countries often exploit impoverished locals by employing them in low-paying jobs amid dangerous working conditions. In some of these cases, the workers are made better off than they otherwise would have been, as there are no more lucrative opportunities for work in their area. However, even if the workers are made better off on balance, it is entirely consistent to say that they are nevertheless wronged by receiving less-than-fair 
compensation for their labour. This points to the more general fact that an act can wrong a person independently of its comparative effect on their overall welfare. It can also wrong them for non-consequentialist reasons as well, e.g. for violating their rights.

Rights-based solutions appeal to this fact in order to account for the moral wrong in (some) $)^{2}$ non-identity cases. Even if a procreative act cannot make a child comparatively worse off, it still may be wrong by violating one or more of that child's rights, such as a putative right against being born into a certain kind of existence. On this view, what is potentially wrong with a case like 14 -Year-Old Girl is not that the child is made any worse off than he otherwise would have been, but rather that he is made worse off than he is entitled to be according to a plausible conception of children's rights: all children arguably have a right to be born into conditions in which they will enjoy minimally decent parental care, and this right was violated by his mother's procreative act. A rights-based solution thus has the advantage of accounting for the moral wrong in non-identity cases while preserving the intuition that it is the resultant child who has been wronged. In other words, it is able to account for the moral wrong in child-affecting terms.

As specified so far, however, a rights-based solution offers only a formal response to non-identity cases, and the extent to which it impugns certain procreative acts will depend on the substantive content of a child's rights. Within the literature, this content differs from theorist to theorist, and is articulated with varying degrees of specificity. For instance, Bonnie Steinbock $(2009,163)$ claims that every child has a right to a life that 'holds a reasonable promise of containing the things that make human lives good', such as 'an ability to experience pleasure, to learn, [and] to have relationships with others'. Alternatively, David Archard $(2004,406)$ claims that a child has a right to a life in which they can enjoy a significant number of the rights articulated within the United Nations Convention on the Rights of the Child (1989), which include but extend far beyond the 
minimal criteria mentioned by Steinbock. In this sense, while all rights-based solutions include what Archard calls a 'birthright claim', or the notion that all children have a right to a standard of living above a certain threshold, exactly where that threshold is set is a matter of reasonable disagreement.

I will not be concerned with defending a particular threshold at this stage, as I am mainly concerned with formal objections that have been raised against rights-based solutions, and with one exception noted below, these objections apply regardless of where the threshold is set. Rather, I will simply assume for the sake of argument a sufficientarian threshold that focuses on children's basic welfare interests, or the interests that must be satisfied for them to lead minimally decent lives as children and to grow into independent and functional adults. This modest conception of children's rights enjoys widespread support in the existing literature on family justice (see, for example, Brighouse and Swift, 2014, chapter 3, esp. 62-70) and can be understood to follow straightforwardly from the interest theory of rights, according to which ' $\mathrm{X}$ has a right if (and only if) an aspect of X's well-being (his interest) is a sufficient reason for holding some other person(s) to be under a duty' (Raz, 1986, 166). ${ }^{3}$ At minimum, I take the relevant interests to include an interest in adequate health, nutrition, shelter, protection from neglect and abuse, and access to adequate parental care, though others may be reasonably added to this list. On this view, what all children have a right to is to be born into conditions in which their basic welfare interests can be satisfied for the duration of their childhood. Accordingly, intentionally creating a child amid conditions in which those interests cannot be satisfied violates that child's rights and constitutes a wrong to that child.

I will address five prominent objections to this view in the following section, though before doing so, it is first necessary to sideline an important objection to the idea of positing a rights threshold in the first place, particularly one that is set above the more 
minimal standard of a 'life worth living'. One common worry about rights-based solutions in general is that they can seem suspiciously ad hoc: while appealing to a child's right to be born into minimally decent conditions might allow us to account for the moral wrong in (some) non-identity cases, it is not always clear that we have reason for attributing such a right to children independently of the fact that it allows us to account for that moral wrong (Boonin, 2014, 109-119; Wasserman, 2015, 230-236). Moreover, critics who advance this worry typically point out that we $d o$ seem to have independent reason for attributing to children a more minimal right to a 'life worth living', for if their lives are not worth living — in the sense that non-existence would be rationally preferable (Feinberg, 1992, 16-17) — then they can coherently claim to have been made worse off by being brought into existence.

Do these considerations undermine the sufficientarian view outlined above? Not necessarily, for two reasons. First, it seems clear that we do have independent reason for attributing to children a right to be born into conditions in which their basic welfare interests can be satisfied for the duration of their childhood. This right, attributed to all future children, is simply a corollary of the rights that all existent children have once they are born. Thus, to the extent that we have independent reason for attributing $x$ rights to existent children, we also have independent reason for attributing to future children a right to be born into conditions in which $x$ rights can be fulfilled (Archard, 2004, 404). We can reasonably disagree about what these rights are, though it is reasonable to think they include (at the very least) rights to the satisfaction of the basic interests children require to lead minimally decent lives.

Second, once we separate the notions of harming and wronging in the way that a rights-based solution suggests, the more minimal threshold of a 'life worth living' begins to look ad hoc itself. Standard analysis of the non-identity problem typically includes an 
exception for cases involving lives not worth living, for in these types of cases, we can coherently claim that a person has been made worse off by being brought into existence. However, if being wronged is not coextensive with being harmed, then it is not clear why comparative worsening should be a necessary condition of wrongdoing in procreative cases. The mere fact that a child has not been made worse off by being brought into existence does not tell us anything about whether she has been wronged unless we assume that children are only entitled to lives worth living. ${ }^{4}$ However, it is unclear what independent reason we have to make this assumption. In addition to negative rights not to be harmed in various ways, we normally take children to have positive rights to the provision of basic goods and opportunities like those listed above. To the extent that this is correct, a sufficientarian threshold based on children's basic welfare interests is more independently justifiable than a lower threshold based on a life worth living, as it is rooted in a more familiar and ultimately more plausible conception of children's rights.

\section{Objections}

Even if we drop assumption (3), and insist that a child may be wronged by being born into disadvantaged conditions without being made comparatively worse off by it, vestiges of the non-identity problem remain insofar as that child's numerical identity is tied to the timing of conception. Parfit $(1984,364)$ points this out by claiming that a child who has his rights violated through a procreative act could not have had his rights fulfilled, for his parents could not have had him by conceiving under more favourable conditions, but only a better off, different child. If 'ought' implies 'can', the fact of nonidentity might appear to get his parents off the moral hook. After all, if his rights could not possibly have been fulfilled, in what sense could his parents have violated them? 
One way of responding to this point is to simply reframe the moral wrong in terms of creating a child whose rights cannot be fulfilled, something Woodward $(1986,815)$ likens to making a promise you know you cannot keep (for a similar argument, see also Tooley, 1998, 119-122). However, even this qualified view is open to a number of possible objections, each of which challenges the invocation of rights in procreative contexts.

\section{Identifiability}

The first objection insists that future children do not satisfy a necessary condition of rights-ascription, and therefore cannot be said to have their rights violated through a procreative act. David Heyd $(2009,13)$ notes that in our usual understanding, rights seem to be linked to metaphysically identifiable people who are the subjects of those rights and the recipients of their correlative duties. For instance, in the case of Smith, we are able to pick out a particular person who is the subject of a right not to be discriminated against, and thus a particular person to whom a duty of non-discrimination is owed. It then makes sense to say that Smith's rights were violated because the airline failed to perform a duty owed specifically to Smith as an identifiable person.

Future children, however, are not identifiable in this way. As Michael Bayles $(1976,300)$ points out, there are deep epistemic limitations to identifying the future children who we might create, as the designator 'future child' may refer to any of the possible children we might create depending on which sperm fertilizes which egg. In this sense, it is not clear to whom, exactly, our procreative duties are owed. But as Heyd makes clear, the problem of identifiability runs even deeper than this, for it is not only that the identities of future children are beyond human knowledge - they are also wholly dependent on human choice. Future children are not concrete individuals 'waiting in the wings', so to speak, but depend for their identity on the human choices that bring about their 
conception. Ascribing rights to future children might then seem paradoxical, for if the identity of a future child depends on our choices, how can those same choices be constrained by a consideration for its rights? Heyd concludes that they cannot be, and that to apply rights in non-identity cases is to ignore their sui generis nature.

Is the identifiability objection sound? Perhaps partly. It is true that among the future children implicated by our procreative choices, there is no numerically identifiable person to whom we can ascribe a right, and thus no particular person to whom we can owe a correlative duty. But this fact is only normatively significant if we accept Heyd's assumption that rights must be linked to metaphysically identifiable people. This assumption seems false, however, and oddly out of touch with common understandings of how rights function. On one plausible understanding, rights do not attach to people's numerical identities, but rather to the kinds of creatures they are, and the positions they occupy in relation to others. What is relevant to the ascription of rights, then, is not a person's numerical identity, but rather their relevant type-description, or the normatively significant set of characteristics that indicates what kind of creature they are, and what kinds of interests they have (Kumar, 2003, 111). ${ }^{5}$ To see this point more clearly, consider once again the case of Smith. It is true that the individual Smith had a right not to be discriminated against, and that by refusing to sell him a ticket, the airline violated Smith's right. But Smith did not hold this right by virtue of being Smith, i.e. Smith, born June 17, 1952, on the basis of a prior conception that brought together a particular combination of $\mathrm{Mr}$. and Mrs. Smith's reproductive gametes. Rather, Smith held this right on the basis of particular characteristics indicative of his type, i.e. a citizen who stands in a particular relation of equality to others. This right is also held by Jones, Brown, Wilson, and all the other citizens who share those particular characteristics, and the airline would have violated their rights in the same way by refusing to sell them tickets. 
The non-identifiability of future children should not prevent us from thinking about them as rights-holders to whom particular duties are owed, for we still know the kinds of creatures they will become, and thus the kinds of interests they are likely to have. Regardless of their numerical identities, all children have certain interests qua children, the satisfaction of which is necessary for them to lead minimally decent lives. Thus, our procreative duties are owed to all the future children who we create, whoever they turn out to be. ${ }^{6}$ To this end, their numerical identities are not morally important. ${ }^{7}$

\section{Non-existence}

Even if we pursue this line of reasoning and regard future children as a class of persons with antecedently identifiable interests, their eligibility as right-holders might be attacked from a different angle. In the existing literature surrounding intergenerational justice, many commentators have denied that rights can be ascribed now to members of future generations who do not currently exist (Beckerman and Pasek, 2001; De George, 1979; Macklin, 1981). The thought behind this claim is that the possession of rights necessarily presupposes the existence of the being who possesses them, such that 'the ascription of rights is [only] made to actual persons - not possible persons' (Macklin, 1981, 151-152). On this view, members of future generations will come to have rights when they exist, but they cannot currently possess rights that impose correlative obligations on members of the present.

A similar objection might be raised in the smaller-scale context of procreation. While future children will come to have rights when they exist, their present non-existence might be thought to imply that they cannot currently possess rights that impose constraints on our procreative behaviour. At the very least, any claim to the contrary would seem to rely on the controversial metaphysical claim that non-existent entities can possess 
real properties, and to the extent that we reject such a claim, we may be led to reject the notion that future children possess rights.

Is the non-existence objection sound? Again, perhaps partly. There is a coherent argument for the claim that future persons cannot possess now, expressed in the following set of premises:

(1) in order to possess rights, one must have interests;

(2) in order to have interests, one must exist;

(3) future persons do not presently exist; therefore,

(4) future persons cannot presently possess rights.

However, the fact that future persons cannot possess rights now does not preclude the possibility that we can have present obligations that are grounded in rights they will possess in the future. As an example of a case that illustrates this possibility, consider Joel Feinberg's $(1984,97)$ kindergarten bomber:

Imagine if you can a criminal so wicked that he wishes to blow up a schoolhouse to kill or mutilate pupils. He conceals a powerful bomb in the closet of the kindergarten room and sets a timing device to go off in six years' time. Six years later the bomb explodes, killing or mutilating dozens of five-year-old children.

The five-year-old victims in Feinberg's example did not exist, and hence did not possess rights, at the time the bomb was planted, though this fact alone does not seem to preclude a rights-based objection to the criminal's act. At the time of his act, he knew (or at least had reason to expect) that there would be children present when the bomb exploded, and that these children would then possess rights not to be killed or mutilated. Thus, there is 
nothing incoherent about claiming that the criminal had an obligation, grounded in the future rights of future children, to refrain from planting the bomb.

The children who we bring into existence through our procreative choices can similarly be thought of as future right-holders: when they come into existence, they will then have rights to the satisfaction of certain basic interests, and will therefore be wronged when they are born into conditions in which those interests cannot be satisfied. Thus, it does not matter that the child of the fourteen-year-old girl does not exist at the time of her procreative decision, for we can still frame an objection to her decision that appeals to the rights he will possess upon coming into existence.

One might object that the preceding response to the non-existence objection is actually a red herring, for the children in non-identity cases are not (yet) future children who will exist in the future, but are rather possible children who may or may not exist in the future depending on the outcome of a particular choice. ${ }^{8}$ Thus, we cannot appeal to the rights of a child who will exist in the future in order to guide that choice, as the choice will in fact determine whether such a child ever exists. However, if we cannot appeal to the rights of a child who will exist in the future in order to guide such a choice, then it is not immediately clear how the preceding response to the non-existence objection is relevant for non-identity cases. Indeed, while we may have present obligations that are grounded in the rights of persons who will exist in the future, it does not necessarily follow that we have present obligations that are grounded in the rights of persons who might exist in the future.

There is a simple response to this objection that draws upon the previous response to the non-existence objection. The possible children in non-identity cases are possible future persons, and can therefore be thought of as contingent future right-holders: if they are brought into existence, they will then have rights to the satisfaction of certain basic 
interests, and will therefore be wronged if they are born into conditions in which those interests cannot be satisfied. Thus, when we refrain from creating such a person, we are not doing so out of concern for a (merely) possible person who is now spared a subthreshold existence (though see Hare, 2007, for an argument to the contrary) but rather out of concern for the actual person who would have been born into sub-threshold conditions had we created them. Notice, however, that in cases where children are in fact born into sub-threshold conditions, we still need a response to the potential objection, raised ex post, that they could not have had their rights violated because they did not exist at the time of the act that resulted in the violation of their rights. The original response to the non-existence objection is therefore not a red herring, but rather a necessary component of our ex post judgment that the decision to create such a child was morally wrong.

\section{Waiving of Rights}

Suppose then that it is intelligible to think of future children as future rights-holders, and that their rights may be violated when they are born into conditions in which their basic welfare interests cannot be satisfied. A further problem arises from the fact that such children may not regret the rights violation insofar as their existence depended on it occurring. Parfit $(1984,364)$ makes this point by citing a letter from The Times, written in response to a British politician who welcomed the fact that there had been fewer teenage pregnancies than the previous year. The man who wrote the letter had been born to a fourteen-year-old mother, and while he did have a difficult upbringing, he now enjoyed his life and balked at the suggestion that it would have been better had he never existed. According to Parfit, this man's reaction undermines rights-based objections to his mother's procreative conduct, for even if we claim that his mother violated his rights by bringing him into disadvantaged conditions, he might then decide to waive those rights to 
the extent that he is happy to be alive. The possibility of waiving rights might seem to diminish the significance of rights violations in procreative contexts. After all, in what sense is a rights violation objectionable if it is not regretted, and is even celebrated, by the supposed victim?

There are two different ways that we might go about responding to the waiving of rights objection. The first is to challenge the significance of a child's lack of regret by pointing to an intuitive asymmetry between the benchmarks associated with starting and continuing lives. According to some theorists, we tend to assign a higher benchmark to starting lives than we do to continuing them, such that we may judge our lives to be worth continuing with certain disadvantages, but also think that it is better not to start a life with the same disadvantages (Benatar, 2006, 22-28; Velleman, 2008, 273-274; Steinbock, 2009, 165-166). For example, David Benatar (2006, 23) notes that, 'while most people think that living life without a limb does not make life so bad that it is worth ending, most (of the same) people also think that it is better not to bring into existence somebody who will lack a limb'. This asymmetry might be thought to undermine the significance of a child's lack of regret, for the fact that a child (or child-as-adult) judges their life to be worth continuing does not necessarily tell us anything about whether it was permissible to initiate in the first place. David Velleman $(2008,274)$ appears to draw this conclusion, claiming that 'we can hardly justify initiating a life on the mere grounds that there would not immediately be reason to terminate it'.

Of course, this response depends on an intuitive judgment that is not universally shared, and thus may be open to an easy counter-response: perhaps the fact that life would still be worth continuing after losing a limb simply indicates that starting a life without a limb would not be so bad (Bayne, 2010). And if we take the benchmarks associated with starting and continuing lives to be symmetrical in this way, we might then consider a 
child's lack of regret to be centrally important, as the fact that a child judges his life to be worth continuing might suggest that it was permissible to initiate in the first place, despite the fact that his rights have been violated.

A second and more promising way of responding to the waiving of rights objection is to challenge its underlying principle of consent. Notice that the waiving of rights objection turns crucially on a principle of consent, or the idea that right-violating conduct can be rendered permissible by receiving the free consent of the person whom it affects. This idea is uncontroversial in cases where the person in question is available to offer their consent. For instance, while my right to bodily integrity prevents you from permissibly cutting me with a scalpel, I might choose to waive that right with respect to you by allowing you to perform surgery on my heart. Assuming I was not coerced, deceived, and had adequate knowledge of the relevant facts and risks, I have meaningfully consented to the surgery, and you do no wrong by cutting me.

In the case of procreation, however, we cannot obtain the consent of the child prior to act that violates their rights, for the act that violates their rights is also a necessary condition of their existence. Does this fact alone undermine the waiving of rights objection? Not necessarily, for as proponents have pointed out, it is not always necessary to secure a person's consent prior to engaging in a presumptively right-violating act—rather, it is sometimes sufficient that the person would hypothetically consent were they able to do so at the time of the act, or that they will subsequently consent at a later time (Boonin, $2014,120)$. For example, suppose that I am unconscious because of my heart condition and you perform life-saving surgery on me without first obtaining my consent. In this case, it is true that I have not consented to the surgery, though it still seems permissible for you to perform it given the strong likelihood that (a) I would have consented to it had I been able to do so at the time of the surgery, or (b) I will consent to it later upon regaining 
consciousness. According to David Boonin (2014, 119-123, 257-268), this type of example provides a strong basis for the waiving of rights objection, for even if a child cannot consent to being born into sub-threshold conditions, it is reasonable to think that (a) they would have consented to it had they been able to do so, or (b) they will consent to it at a later time.

Do either of these possibilities undermine the proposed rights-based solution? Consider first the possibility of hypothetical consent. Initially, it might seem reasonable to think that if they were given the opportunity and made aware of the available options, a child would choose to waive their right to be born into minimally decent conditions rather than to never exist at all. However, there are at least two problems with this type of reasoning. First, and most importantly, the case of procreation is disanalogous to the case of surgery in a way that makes an appeal to hypothetical consent problematic. When we infer hypothetical consent in the case of the unconscious patient, we are assuming they would have consented to the surgery at the moment it was performed. This is a reasonable assumption in most cases, as people typically have an interest in continuing to exist, and would thereby be deprived by ceasing to exist. However, this type of assumption cannot play the same justificatory role in cases of procreation, for prior to the moment a child is created, there is no existent person who might have given their consent to being born into sub-threshold conditions - rather, there is only a possible person at that moment, one who will be wronged if they are born into sub-threshold conditions, but who will not otherwise be deprived if they are never created. An appeal to hypothetical consent is therefore incoherent, for it falsely attributes to possible people an interest they can only have once they exist.

However, even if hypothetical consent could be appealed to in the way that Boonin describes, a second problem is that the circumstances seem like those in which 
the inferred consent would not be morally binding. Suppose that it makes sense for us to imagine a possible person prior to existence who is faced with the choice of either existing in sub-threshold conditions or never existing at all. Even if it were intelligible to assume that such a person has an interest in existence, and would thereby choose the former over the latter option, it is not clear that this has the normative relevance Boonin ascribes to it, as their situation resembles one in which consent is obtained under conditions of duress (see Reiman, 2007, 88, and Hurley and Weinberg, 2015, 720 for similar arguments). If I hold a gun to your head and offer you a choice between your money or your life, it is reasonable to assume that you would agree to hand over your money. However, this type of agreement has no moral force, as consent that is obtained under an unjust threat of violence is not a morally binding form of consent. By parity of reasoning, consent to a rights-violation that is obtained under a structurally similar threat of non-existence does not seem like a morally binding form of consent. Children in such a scenario face an option set that is itself unjust, so their hypothetical preference for the less bad option should not be taken as an exculpating factor in the violation of their rights. ${ }^{9}$

Taken together, these two problems severely undermine the hypothetical consent interpretation of the waiving of rights objection: not only is it incoherent to appeal to hypothetical consent in procreative contexts, but even if it were coherent, the inferred consent would be tainted in a way that renders it morally inert. But what about the subsequent consent interpretation, according to which children (or the adults they become) later consent to being born into sub-threshold conditions? This interpretation, reflected in Parfit's original example, might seem more promising given the fact that existing persons can and often do express an appreciation for having been born, even when they have been born into disadvantaged conditions. Can the expectation that a child will subsequently 
waive their right to be born into minimally decent conditions justify the violation of that right?

I do not believe that it can, for a combination of reasons. First, and at a general level, it is not clear that an appeal to subsequent consent actually does any justificatory work in the analogous surgery case. This can be revealed by considering a modified version in which subsequent consent is withheld. Imagine that, upon regaining consciousness, I object to your surgery on the grounds that my religious commitments preclude medical interventions in my body. It seems clear that my withholding of subsequent consent does nothing to affect the permissibility of the surgery, for at the time of the surgery, it was reasonable to assume that I had an interest in continuing to exist and would therefore have offered my consent. However, if the denial of subsequent consent does nothing to render the surgery impermissible, then it is not clear what the obtainment of subsequent consent does to render it permissible. Indeed, it seems like what is really doing the work in this type of case is the reasonable expectation that I would have consented to the surgery at the moment it was performed, though this appeal to hypothetical consent is not applicable in procreative cases.

One might object that it is not the actual obtainment of subsequent consent that justifies presumptively right-violating conduct, but rather the reasonable expectation that subsequent consent will be offered. Thus, it does not matter that a person actually withholds their consent after the fact so long as it was reasonable to expect that they would provide it. This interpretation of subsequent consent survives the previous objection, but it is also implausible as a general principle, for it would seem to permit right-violating conduct that had the effect of increasing the probability of subsequent consent. For example, suppose that you and your associates find me unconscious one day and perform a sophisticated brainwashing technique that wins my allegiance to your cult. Suppose 
further that this was the only time the technique could be performed, such that it was not possible to secure my consent beforehand. If the reasonable expectation of subsequent consent is sufficient to render a right-violating act permissible, then it seems that you have acted permissibly, for given the effect of the brainwashing technique, it was reasonable for you to expect that I would later consent to your actions. This, however, is a bizarre implication. It is clearly impermissible for you to brainwash me, and at least one explanation for this is supplied by the inapplicable principle of hypothetical consent: given my interests at the time I became unconscious, it was not reasonable to expect that I would have consented to being brainwashed.

Of course, one might object further that the consent offered in this example would not be morally binding given that it was offered under the judgment-corrupting influence of the brainwashing technique. This line of objection might seem promising, though it does not actually help proponents of the waiving of rights objection, for as many theorists have noted, human existence contains its own judgment-corrupting influences that predispose people toward existence and make it more likely that they will subsequently consent to having been born into sub-threshold conditions. For example, many theorists have noted the deceptive role that various psychological phenomena play in our subjective quality of life assessments, including positivity bias, status quo bias, and preference adaptation (for a useful overview of these phenomena and their relevance for procreative decision-making, see Marsh, 2014). One potential effect of these phenomena is to make us subjectively satisfied with unsatisfactory states of affairs, leading us to question whether a child's subsequent consent can be sufficiently informed to justify the violation of their right. However, in addition to these general phenomena, there is also a more specific judgment-corrupting influence at work in the subsequent waiver scenario, which is the false sense of deprivation involved in comparing one's current existence with a 
counterfactual scenario in which one never existed. When we ask a presently existing person whether they would prefer existing in their disadvantaged condition to having never existed at all, we are asking them a loaded question, for the experience of existence makes it very difficult to imagine non-existence in anything but a negative light. Indeed, by inviting a person to consider a counterfactual scenario in which they never existed, we are implicitly directing their attention toward the various goods in their life they would have 'missed out on', making their counterfactual non-existence seem inherently deprived by comparison. However, in a subsequent waiver scenario, this is problematic for two reasons. First, unlike death, preconception non-existence is not in fact a deprived condition, as there are no goods in that condition to be deprived of, and no person to be deprived of them (Cohen, 1997, 33-35). The sense that it is a deprived condition is merely the product a faulty ex post comparison that considers information irrelevant to the evaluation of the alternative scenario: had the child never existed, he would not have experienced the goods of existence, and would therefore not have been deprived by their absence. Second, to the extent that it is foreseeable that a child will view their counterfactual non-existence as a deprived condition, the case of bringing a child into sub-threshold conditions exhibits the same problematic features as the brainwashing case presented above: it is a rights-violation that has the effect of increasing the probability of subsequent consent by means of a judgment-corrupting influence. Thus, the consent that is subsequently offered cannot serve a justificatory role in the violation of that right, as it is again tainted a way that renders it morally inert.

One might wonder whether this view implies that other proposed standards for valid life-affirmation — such as David DeGrazia's $(2012,158)$ principle of 'undeluded gladness' - are difficult or impossible to come by. I am unsure about this strong view, though given the various factors that bias one toward affirming existence even under 
adverse conditions, I do not think that we can point to a child's subsequent gladness to be alive to justify the violation of his rights. The point is not only that the child might be deluded in a way that invalidates his subsequent consent, but also that he is taken advantage of in an unfair way. His parents are able to shirk their duties of procreative care with respect to him in the reasonable expectation he will later absolve them of their wrongdoing, as his experience of existence will predispose him to favour it over a counterfactual scenario in which he never exists. The fact that the deck is stacked in favour of their exculpation should lead us to seriously question the moral relevance of any subsequent consent that is offered (for a related though distinct view about a child's inevitable self-attachment to his own regrettable existence, see Velleman, 2008, 272).

\section{Lack of Legitimate Complaint}

A related but even deeper worry is that even if a child did not waive their rights and were to protest their violation, they would nevertheless lack a legitimate complaint against their progenitors insofar as the only alternative to having their rights violated was non-existence. This has often been the verdict in so-called 'wrongful life' torts, in which a child (or their representative) claims damages against their parents or others for bringing them into a miserable, disadvantaged, or unwanted life. Courts have typically rejected such claims on the grounds that they depend on an impossible comparison between the value of non-existence relative to existence, which does not allow for the establishment of injury on the part of the child. As one judge wrote in response to a case in which a doctor was sued for permitting the birth of a severely disabled child,

sympathy for a handicapped child and his parents should not lead us to ignore the notions of responsibility, causation, and damage that underlie the entire philosophy of our system of justice. It 
would be unwise - and, what is more, unjust - to permit the plaintiff to recover damages from persons who caused him no injury (as quoted in Steinbock, 1986, 18).

Now in one sense, this common objection to wrongful life torts simply begs the question against rights-based solutions, as it relies on the contentious 'no worse off' argument that such solutions reject. Conceiving of injury as the comparative worsening of one's condition, it deduces that the child has not been injured in wrongful life cases because she cannot be shown to have been made worse off than she otherwise would have been (as such a judgment would entail an allegedly impossible comparison between the value of a defective life and no life at all). But this is the very premise that rights-based solutions seek to discredit. Even if a child cannot be made comparatively worse off by a procreative act, she may nevertheless be wronged by being born into conditions in which her basic welfare interests cannot be satisfied. Viewed in this way, such a child does appear to have a legitimate moral complaint against those responsible for her birth: that her rights have been violated, or that she has been born into conditions in which her rights cannot be fulfilled.

In another sense, however, this common objection to wrongful life torts might indicate a much more problematic notion for rights-based solutions, namely, that there are cases in which a person lacks a legitimate complaint for having their rights violated. As an example of a case that might fit this description, consider another surgery case, based on one originally introduced by Parfit $(1986,855)$. Suppose that you are unconscious after a car accident. Your arm, currently lodged under one of the vehicles, must be amputated imminently in order to save your life. Fortunately, a surgeon happens to be on scene to perform the operation. Knowing what he must do, he successfully amputates your arm, thereby saving your life. 
The accident case appears to be one in which the violation of a person's rights does not affect the permissibility of the act in question. It is true that by amputating your arm without your consent, the surgeon violates a number of your rights, including your right to bodily integrity. However, given the available alternatives, the violation of that right does not provide a strong reason against amputating your arm. If the surgeon does not amputate your arm, your right to bodily integrity will be respected, but only at the much higher cost of your life. In this sense, even though the surgeon has violated your rights, you appear to lack a legitimate complaint against him insofar as you would have died otherwise.

An analogy with the accident case appears to undermine the significance of rights violations in procreative contexts. Just as your rights were violated by the surgeon amputating your arm without your consent, so too is a child's rights violated when he is born into conditions in which his basic welfare interests cannot be satisfied; and just as you lack a legitimate complaint against the surgeon insofar as your life depended on him violating your rights, so too does a child lack a legitimate complaint against his parents insofar as his life depended on them violating his rights. If sound, this analogy serves as a compelling reductio ad absurdum, for if we want to claim that a child does in fact have a legitimate complaint against his parents, we seem forced to take on board the more counterintuitive claim that you also have a legitimate complaint against the surgeon, and that his act was therefore impermissible.

However, there are at least two important differences between the procreative context and the accident case that preclude such an analogy, and which by extension undermine the lack of legitimate complaint objection as a whole. The first difference involves the consequences of not acting, or of refraining from engaging in the right-violating conduct. By not acting in the accident case, the surgeon allows you to die, which 
results in an even worse outcome ${ }^{10}$ from the perspective of your own interests, and which may also violate a general duty of easy rescue. However, by not acting in the procreative context, there is no comparable loss: the parents would not be allowing a worse outcome to occur - a possible child is not made worse off by never existing - and assuming that there is no duty to procreate, they would not be violating any duties owed to particular people (see Shiffrin, 1999 for a similar argument). Thus, while there are strong reasons in favour of acting in the accident case — in light of the consequences of not acting - there are only reasons against acting in the procreative case, suggesting that the violation of a child's right to a minimally decent existence is not analogous to the violation of your right to bodily integrity. This disanalogy is significant in the present context because it provides the surgeon with a justification for his actions that parents lack: if he does not violate your rights, then things will go worse for you. ${ }^{11}$

However, a second and arguably more important difference between the two cases involves the causal relationship between the right violator(s) and the circumstances of the rights violation. In the accident case, you were by chance put in a position where the only available options were to have your arm amputated or to die, a circumstance that apparently leaves you with no legitimate complaint against the surgeon for violating your rights. However, in the procreative context, the parents are responsible for creating the comparable circumstance. By conceiving amid conditions in which their child's rights could not be satisfied, they electively put him in a position where he lacks a legitimate complaint against them, insofar as the only alternative to having his rights violated was to never exist. A truly analogous accident case would then be one in which the surgeon was responsible for putting you in a position where the only available options were to have your arm amputated or to die - perhaps he was in the other vehicle and deliberately crashed into you to perform a surgery. However, in this revised accident case, it would 
seem odd to attach significance to the fact that you lack a legitimate complaint against the surgeon, for he is responsible for putting you in that compromised position: had he acted with due consideration for your interests, you would not have been in a circumstance where the best available option was to have your arm amputated. In a similar vein, it seems misguided to attach moral significance to a child's apparent lack of complaint against his parents. Had his parents acted with due consideration for his interests - or, more accurately, the interests of whatever child they might have created - he would not have been put in a position where having his rights violated was the best available option for him. The fact that he would not have existed otherwise should not get his parents off the moral hook, for they still appear to have done wrong: not only for creating a child whose rights could not be fulfilled, but also for putting him in a position where the cost of protesting that injustice is denouncing his own existence.

When reflecting on this response to the lack of legitimate complaint objection, one might wonder whether it is always appropriate to think of a child's parents as electively putting him in a position where having his rights violated was the best available option for him. For instance, in cases where a child's basic welfare interests cannot be satisfied because of a serious congenital disorder, it might seem more appropriate to say that the disorder, rather than the parents, is responsible for putting the child in a disadvantaged condition. But if this is the case, there seems to be a relevant disanalogy between the case of procreation and the revised accident case presented above, for while the surgeon is responsible for creating the limited option set faced by the accident victim, a set of procreators cannot always be held responsible for the limited option set faced by their progeny.

Does this disanalogy undermine the argument at hand? Not necessarily, for even if procreators are not responsible for the limited option set faced by their progeny, they 
are still responsible for creating a child who will foreseeably face a limited option set, and this is sufficient to establish the moral wrong. To illustrate the plausibility of this reasoning, consider the following pair of cases. Imagine that I promise to help you paint your house, and then renege on that promise because I am too hungover to perform physical labour. In this case, I have wronged you by failing to fulfil my promise and I am responsible for my inability to fulfil that promise-I should not have had so much to drink the night before I agreed to paint your house. Now imagine an alternative case in which I promise to help you paint your house knowing that my heart condition precludes me from performing physical labour. In this case, I am not responsible for my inability to fulfil my promise - this is due to my heart condition - though I have still wronged you in a virtually identical sense by making a promise I knew I would not be able to fulfil. By parity of reasoning, even if procreators are not directly responsible for the non-fulfilment of their child's rights, they still wrong their child by creating her amid conditions in which they know her rights will go unfulfilled. That this outcome is foreseeable at the time of the child's conception is sufficient to render their act of procreation wrongful.

\section{Unfairness}

A fifth and final objection focuses not on the intelligibility of attributing sufficientarian rights to future children, but rather on the potentially unattractive normative implications of doing so (Wasserman, 2005, 137-138; DeGrazia, 2012, 167-169). As David Wasserman $(2005,138)$ writes,

the claim that children are entitled to the satisfaction of such a higher standard [than a life worth living], even if unavoidable impairment precludes it, seems ad hoc, with disturbing implications. It would condemn parents of limited means and prospects, or in hostile or unstable social 
environments, from having any children, even children expected to have lives worth living despite their privations and hardships. The harshness of this judgment remains even if we excuse parents for the rights violation if they cannot have a child who exceeds the threshold.

Wasserman's worry can be understood as one about unfairness to potential procreators, particularly those who are unable to secure minimally decent conditions for their progeny due to circumstances beyond their control. Does this type of worry provide grounds for rejecting the proposed rights-based solution?

As a preliminary response, it is worth noting that Wasserman does not deny the claim that giving due consideration to children's interests implies that some persons are unable to procreate permissibly - on the contrary, he concedes that persons who are unable to provide their children with 'lives worth living' are morally prohibited from procreating, even when that inability is due to circumstances beyond their control (Wasserman, $2005,135)$. In this sense, Wasserman's objection has more to do with where a rights threshold is set, rather than the very idea of a rights threshold itself. Indeed, the crux of his objection seems to be that higher thresholds fail to strike an appropriate balance between the interests of procreators and the interests of progeny, and in so doing, exclude too many people from permissibly having children.

One possible response to this objection is to exempt procreators from the requirement to secure minimally decent conditions for their children when their inability to meet that requirement is due to circumstances beyond their control. This is the approach taken by DeGrazia $(2012,168)$, for example, who claims that disadvantaged prospective parents are morally 'off the hook in those circumstances in which their inability to meet a basic need [for their children] is a consequence of external circumstances and not their own character deficits or pathology'. However, it is not clear that Wasserman's objection necessitates this type of conciliatory response. It is certainly regrettable that some persons 
will, through no fault of their own, be unable to permissibly pursue their procreative projects, and depending on how much value we attach to procreation, this might give us an additional reason to address the various structural injustices that put persons at such a disadvantage. However, provided that we have good independent grounds for attributing to children the rights in question, it is unclear why this provides a reason to reject a rightsbased solution to the non-identity problem. Consider, by way of analogy, how this reasoning would reduce to absurdity if applied in a structurally similar context. It is generally accepted that children have a right to a minimally decent upbringing, and that parents who are either unable or unwilling to provide such an upbringing are morally ineligible to parent. In this case, attaching a certain amount of weight to children's interests has the effect of disqualifying certain individuals from permissibly parenting, even when their inability to satisfy a child's interests is due to circumstances for which they are not personally responsible, e.g. a lack of parenting competence that is rooted in a traumatic upbringing of their own. However, the bare fact that a particular conception of children's rights disqualifies some persons from permissibly parenting does not necessarily count as a consideration against that conception. While we might have an obligation to offer assistance to such people, or to take certain measures to improve their capacities or resources, it is an odd response to increase their eligibility by weakening our conception of children's rights.

By parity of reasoning, the bare fact that a particular conception of children's rights disqualifies some persons from permissibly procreating does not necessarily count as a consideration against that conception. While it plausibly generates duties of assistance toward such persons, and diminishes the extent to which they are to blame for bringing children into sub-threshold conditions, it does not necessarily impact on the separate issue of whether those children have been wronged by being brought into existence. 


\section{References}

Archard, David. 2004. "Wrongful Life," Philosophy, 79(309): 403-420.

Bayles, Michael. 1976. "Harm to the Unconceived," Philosophy and Public Affairs, 5(3): 292-304.

Bayne, Tim. 2010. "In Defense of Genethical Parity" in David Archard and David Benatar eds. Procreation and Parenthood: The Ethics of Bearing and Rearing Children. Oxford: Oxford University Press.

Beckerman, Wilfred and Joanna Pasek. 2001. Justice, Posterity, and the Environment: Environmental Ethics for a New Millennium. Oxford: Oxford University Press.

Benatar, David. 2006. Better Never to Have Been: The Harm of Coming into Existence. Oxford: Oxford University Press.

Boonin, David. 2014. The Non-Identity Problem and the Ethics of Future People. Oxford: Oxford University Press.

Brighouse, Harry and Adam Swift. 2014. Family Values: The Ethics of Parent-Child Relationships. Princeton: Princeton University Press.

Brock, Dan W. 1995. "Genetic Harms and the Non-identity Problem," Bioethics, 9(3/4): 269-275.

Cohen, Cynthia B. 1997 "The Morality of Knowingly Conceiving Children with Serious Conditions: An Expanded 'Wrongful Life' Standard" in Nick Fotion and Jan C. Heller eds. Contingent Future Persons: On the Ethics of Deciding Who Will Live, or Not, in the Future. Dordrecht: Springer.

De George, Richard. 1979. "The Environment, Rights, and Future Generations," in Kenneth Goodpaster and K.M. Sayre eds. Ethics and Problems of the $21^{\text {st }}$ Century. Notre Dame: Notre Dame University Press.

DeGrazia, David. 2012. Creation Ethics: Reproduction, Genetics, and Quality of Life. Oxford: Oxford University Press.

Elliott, Robert. 1989. "The Rights of Future People," Journal of Applied Philosophy, 6(2): 59-69.

Feinberg, Joel. 1984. Harm to Others, Vol. 1 of The Moral Limits of the Criminal Law. New York: Oxford University Press.

Feinberg, Joel. 1992. "Wrongful Life and the Counterfactual Element in Harming" in Freedom and Fulfillment: Philosophical Essays. Princeton: Princeton University Press.

Hare, Caspar. 2007. "Voices from Another World: Must We Respect the Interests of Per- sons Who Do Not, and Will Never, Exist?” Ethics, 117(3): 498-523.

Harman, Elizabeth. "Can We Harm and Benefit in Creating?" Philosophical Perspectives, 18 (2004), pp. 89-113. 
Heyd, David. 1992. Genethics: Moral Issues in the Creation of People. Berkeley: University of California Press.

Heyd, David. 2009. “The Intractability of the Non-Identity Problem” in Melinda A. Roberts and David T. Wasserman eds. Harming Future Persons. Dordrecht: Springer.

Hurley, Paul and Rivka Weinberg. 2015. "Whose Problem is Non-Identity?" Journal of Moral Philosophy, 12(6): 699-730.

Kavka, Gregory S. 1982. "The Paradox of Future Individuals," Philosophy and Public Affairs, 11(2): 93-112.

Kumar, Rahul. 2003. "Who Can Be Wronged?” Philosophy and Public Affairs, 31(2): 99-118

Macklin, Ruth. 1981. "Can Future Generations Correctly Be Said to Have Rights?" in Ernest Partridge ed. Responsibilities to Future Generations. Buffalo: Prometheus Books.

Marsh, Jason. 2014. "Quality of Life Assessments, Cognitive Reliability, and Procreative Responsibility," Philosophy and Phenomenological Research, 89(2): 436-466.

Mill, John Stuart. 1991. On Liberty and Other Essays. Ed. John Gray. Oxford: Oxford University Press.

Parfit, Derek. 1984. Reasons and Persons. Oxford: Clarendon Press.

Parfit, Derek. 1986. “Comments,” Ethics, 96(4): 832-872.

Raz, Joseph. 1986. The Morality of Freedom. Oxford: Clarendon Press.

Reiman, Jeffrey. 2007. "Being Fair to Future People: The Non-identity Problem in the Original Position," Philosophy and Public Affairs, 35(1): 69-92.

Roberts, Melinda. 1998. Child Versus Childmaker: Future Persons and Present Duties in Ethics and the Law. Oxford: Rowman and Littlefield.

Schwartz, Thomas. 1978. "Obligations to Posterity" in Brian Barry and R.I. Sikora eds. Obligations to Future Generations. Philadelphia: Temple University Press.

Shiffrin, Seana V. 1999. "Wrongful Life, Procreative Responsibility, and the Significance of Harm," Legal Theory, 5: 117-148.

Smolkin, Doran. 1999. "Toward a Rights-Based Solution to the Non-Identity Problem," Journal of Social Philosophy, 30(1):194-208.

Steinbock, Bonnie. 1986. "The Logical Case for 'Wrongful Life'," Hastings Center Report, 16(2): 15-20.

Steinbock, Bonnie. 2009. "Wrongful Life and Procreative Decisions" in Melinda A. Roberts and David T. Wasserman eds. Harming Future Persons: Ethics, Genetics, and the Non-identity Problem. Dordrecht: Springer. 
Tooley, Michael. 1998. "Value, Obligation, and the Asymmetry Question," Bioethics, 12(2): 111-124.

Velleman, J. David. 2008. "Persons in Prospect," Philosophy and Public Affairs, 36(3): 221-288.

Wasserman, David. 2005. "The Non-identity Problem, Disability, and the Role Morality of Prospective Parents," Ethics, 116(1): 132-152.

Wasserman, David. 2015. "Part II: Pro-Natalism" in David Wasserman and David Benatar. Debating Procreation: Is it Wrong to Reproduce? Oxford: Oxford University Press.

Woodward, James. 1986. “The Non-Identity Problem,” Ethics, 96(4): 804-831.

\section{Acknowledgements}

For helpful comments and discussion on previous drafts, I am grateful to Paul Bou-Habib, Dan Butt, Simon Caney, Matthew Clayton, Andreé-Anne Cormier, Anca Gheaus, Darien Heim, Serena Olsaretti, Julian Savulescu, Isabella Trifan, Zofia Stemplowska, audiences in Oxford and Barcelona, and three anonymous reviewers for this journal.

\section{Funding}

Research for this project was supported by the European Research Council (ERC) project on Justice and the Family: An Analysis of the Normative Significance of Procreation and Parenthood in a Just Society, under the European Union's Horizon 2020 Research and Innovation programme (Grant Agreement Number: 648610; Grant Acronym: Family Justice) 
${ }^{1}$ Philosophers like Melinda Roberts might point out that the 14-Year-Old Girl is not in fact a pure nonidentity case, for the choice the girl faces is not a '2-alternative' choice between having a disadvantaged child or having no child at all, but is rather a '3-alternative' choice between having a disadvantaged child, having no child at all, or having a child but not exposing him to disadvantage (e.g. by adopting him out to more competent parents who will provide him with a better start in life). Thus, in order for the non-identity problem to genuinely arise in this type of case, we must assume that the child will not in fact have access to better parental care, such that his choice is really between a disadvantaged existence or no existence at all. Notice, however, that we must make similar assumptions in what are commonly regarded as 'pure' nonidentity cases, such as those involving identity-linked congenital impairments: just as we must assume that the child in 14-Year-Old Girl will not have access to better parental care, we must also assume that there will be no cure or effective treatment for the identity-linked impairment that removes its disadvantage. For Roberts' discussion of the 2-alternative/3- alternative distinction, see Roberts, 1998, chapter 3, esp. 94-95.

${ }^{2}$ As I explain in further detail below, whether or not a rights-based approach identifies a moral wrong in a particular non-identity case will depend on the substantive content of a child's rights. Thus, a plausible rights-based approach might only identify a moral wrong in a small subset of cases in which the nonidentity problem arises. This does not constitute a flaw of the rights-based approach, but simply reflects its limited role in our overall assessment of non-identity cases. In cases that do not involve rights-violations, we may need to appeal to other types of considerations in order to frame a moral objection, e.g. impersonal values or parental virtue. For similar pluralistic approaches, see Elliot, 1989, Steinbock 2009, and Woodward, 1986.

${ }^{3}$ Note that this interest theory explanation for a child's right to the satisfaction of her basic welfare interests need not exhaust the range of possible explanations. For example, we might think that such a right can also be derived from contractualist moral principles.

${ }^{4}$ Even if we make this assumption, notice that the relevant explanation for the absence of wrongdoing is not supplied by the fact that the child is not worse off than he otherwise would have been, but rather that he is not worse off than he is entitled to be.

${ }^{5}$ In appealing to Kumar's type/token distinction, I do not intend to endorse its more extended use in his contractualist solution to the non-identity problem. My use of this distinction is more limited and is simply intended the support the idea that it does not matter that prospective parents cannot identify their token future child, as they still know the child will be of a type for whom sub-threshold conditions are bad.

${ }^{6}$ To dispel any mystery associated with this claim, it is worth noting that prospective parents often act in ways that accelerate or postpone childrearing - acts that affect both the identity of the child as well as the prospects of fulfilling the relevant parental duties towards it - whoever 'it' turns out to be. For example, parents choose to have a child while they are young or energetic, or they wait until they are older and more materially comfortable; alternatively, they choose to have a child when they are too young or old to reasonably expect to fulfill their parental duties. These acts are frequently praised or criticized in ways that are fully consistent with a recognition of their identity-affecting character. I am grateful to an anonymous review for suggesting this further explanation.

${ }^{7}$ This is not to say that a child's numerical identity is always morally unimportant for the assessment of rights violations in procreative contexts. For example, it may be morally important whether a prenatal intervention that would have prevented an above-threshold harm to a future child would have also been identity-affecting. If so, the parents have good reason, for the sake of the future child, to decline that intervention. If not, the parents might be violating their duty to protect their child from harm, even if he or she is left above the threshold. I am grateful to an anonymous reviewer for pointing this out. 
${ }^{8}$ I am grateful to an anonymous reviewer for pressing me on this objection.

${ }^{9}$ Boonin anticipates this type of response, though denies that it succeeds across the board, for unlike the person who holds a gun to your head, procreators cannot always be held responsible for the limited option set faced by their progeny. I respond to this distinct worry below in connection with the lack of legitimate complaint objection. For Boonin's articulation of it, see Boonin, 2014, 259-262.

${ }^{10}$ We can understand the worseness of this outcome in a number of different ways. For example, we might think that it is worse by exposing you to an even greater harm than you would experience by having your arm amputated, or we might think that it is worse by allowing an even greater rights violation to occur than the violation of your right to bodily integrity i.e. the violation of your right to life.

${ }^{11}$ An anonymous reviewer posed the following challenge in response to this point: if you can permissibly violate a patient's rights for their own good, then why can't you have a baby at 14 for the baby's own good, even if it will violate her rights? This is a fair challenge, though it under-describes the justification that is available to the surgeon for violating the patient's rights, and thus makes a faulty inference about the analogous case of procreation. The reason why you are not permitted to have a baby at 14 (who we assume will not have access to adequate parental care) is because by doing so you will be violating the baby's rights without an appropriate baby-centered justification: the baby will be wronged if brought into existence under sub-threshold conditions, but will not otherwise be deprived by never existing. By contrast, the surgeon is permitted to violate the rights of the patient because he has an appropriate patient-centered justification: if he does not violate the patient's rights, things will go worse from the perspective of the patient's interests. 